Article

\title{
Formation of Nanoscale Metallic Glassy Particle Reinforced Al-Based Composite Powders by High-Energy Milling
}

\author{
Weiwen Zhang, Yuan Hu, Guanqun Zhang and Zhi Wang * \\ National Engineering Research Center of Near-Net-shape forming for Metallic Materials, South China \\ University of Technology, Guangzhou 510640, China; mewzhang@scut.edu.cn (W.Z.); \\ mayahuyuan@126.com (Y.H.); zgqarticle@163.com (G.Z.) \\ * Correspondence: wangzhi@scut.edu.cn; Tel.: +86-020-8711-3851
}

Received: 8 September 2017; Accepted: 9 October 2017; Published: 12 October 2017

\begin{abstract}
The initial microstructure and mechanical properties of composite powders have a vital role in determining the microstructure and mechanical properties of the subsequent consolidated bulk composites. In this work, Al-based matrix composite powders with a dense and uniform distribution of metallic glass nanoparticles were obtained by high-energy milling. The results show that high-energy milling is an effective method for varying the microstructure and mechanical properties of the composite powders, thereby offering the ability to control the final microstructure and properties of the bulk composites. It was found that the composite powders show a deformed layer combined with an undeformed core after milling. The reinforcements, metallic glass microparticles, are fractured into dense distributed nanoparticles in the deformed layer, owing to the severe plastic deformation, while in the undeformed core, the metallic glass microparticles are maintained. Therefore, a bimodal structure was obtained, showing a mechanical bimodal structure that has much higher hardness in the outer layer than the center core. The hardness of the composite particles increases significantly with increasing milling time, due to dispersion strengthening and work hardening.
\end{abstract}

Keywords: aluminium matrix composites; nanoparticles; metallic glasses; ball milling

\section{Introduction}

Al-based metal matrix composites (AMMCs) have low density, high specific strength, and high specific stiffness [1-5]; thus, they have been considered preferentially as an ideal engineering material for lightweight applications in the aerospace, defense and automotive industries [6,7]. However, AMMCs usually show high strength, but limited ductility, due to the defects that exist in the AMMCs, where cracks and premature failure occur [8]. There are several typical defects that occur in the most common AMMCs (ceramics as reinforcements), such as agglomeration, porosity, and detrimental interfacial reactions, which severely limits their wider application [9-11]. To avoid these defects, non-ceramic reinforcements have been developed, such as metallic glass [12-16], quasicrystalline [17], TNM Ti-Al alloy [18] etc.

Metallic glasses have high strength, large elastic limit, high corrosion resistance, and good wettability with the metal matrix; therefore, they are able to overcome the disadvantages that are commonly associated with conventional ceramic reinforcing phases $[19,20]$. Good bonding between the metallic glass $(\mathrm{MG})$ reinforcements and metal matrices have been observed [1,21-23]. For example, a $5 \mathrm{~nm}$ thickness interdifussion interface layer exists in the Zr-based MG short fiber reinforced Al7075 alloy, and no detrimental intermetallic compounds formed, which is helpful for avoiding crack origination near the interface, and hence improving strength and ductility [1]. Similar results have 
also been reported for $\mathrm{Al}$ matrix composites reinforced with $\mathrm{Ni}-\mathrm{Nb}$ metallic glass particles [4]. Due to the above-mentioned advantages, it has been shown that metallic glass shows excellent strengthening effects in metals such as aluminum [12,21,24,25], magnesium [26] and copper alloys [27,28].

However, despite the high strengthening effect obtained for aluminum and aluminum alloys by adding MG reinforcement, the ductility of these AMMCs is still relatively low [29]. The main reason for this is that the MG reinforcements used are microparticles, where high local stress concentration can occur and cause microcracks [30]. The microcracks can propagate during subsequent loading and plastic deformation, and can finally lead to the failure of composites. It has been proved that nanoparticles have less stress concentration during loading than the microparticles in AMMCs, and therefore have better mechanical properties for the nanocomposites [31,32]. It has been found that both high strength and reasonable ductility can be obtained for the nanocomposites reinforced with ceramic nanoparticles [33]. Similar to ceramic nanoparticle reinforced composites, composites reinforced with MG nanoparticles may have better strength and ductility than MG microparticle reinforced composites, and could be a good candidate for AMMCs in terms of acquiring both high strength and high ductility. However, owing to the difficulty of obtaining MG nanoparticles, preliminary works have mostly focused on micro-sized particle $(>5 \mu \mathrm{m})$ reinforcing composites, and research on nano-sized metallic glass reinforcements has only rarely been performed $[12,15]$. Another challenge is that it is difficult to fabricate the composites with a uniform dispersion of MG nanoparticles [12,22,29]. In this work, a powder metallurgical route was developed to fabricate nanocomposite powder where MG nanoparticles are uniformly distributed in the Al alloy matrix, which may be beneficial for designing and fabricating the novel nanocomposites reinforced with metallic glass nanoparticles.

\section{Materials and Methods}

Initially, $92 \mathrm{vol} \%$ gas atomized Al7075 alloy powders (size: $10 \mu \mathrm{m}$ ) and 8 vol \% MG powders (size: $20-50 \mu \mathrm{m}$ ) were mixed. The chemical composition of the Al7075 aluminum alloy power is shown in Table 1. The composition of MG powder is $\mathrm{Ti}_{52} \mathrm{Cu}_{20} \mathrm{Ni}_{17} \mathrm{Al}_{11}$ and was synthesized by mechanical alloying using a high-energy planetary ball mill (QM-2SP20, Nanjing NanDa Instrument Plant, Nanjing, China). Then, the mixed composite powders were further ball-milled by a QM-2SP20 planetary ball mill with stainless steel balls and vials under a protective argon atmosphere $(99.999 \%$, $0.5 \mathrm{MPa}$ ). The diameters of the stainless steel balls were $15 \mathrm{~mm}, 10 \mathrm{~mm}$, and $6 \mathrm{~mm}$ with a weight ratio of 1:3:1. The ball-to-powder mass ratio was approximately 10:1. A few drops of ethanol were added into the milling vials as a process control agent. The powders were milled at a milling speed of $245 \mathrm{rpm}$ for $10 \mathrm{~h}, 15 \mathrm{~h}, 20 \mathrm{~h}, 30 \mathrm{~h}$ and $50 \mathrm{~h}$, respectively. All samples handling were carried out in a glove box under purified Ar atmosphere in order to minimize atmospheric contamination.

Table 1. The chemical composition of the Al7075 aluminum alloy power.

\begin{tabular}{ccccccccc}
\hline Element & Al & Zn & Mg & Cu & Fe & Mn & Si & Cr \\
\hline wt $\%$ & Base & 5.38 & 2.48 & 1.48 & 0.22 & 0.24 & 0.15 & 0.18 \\
\hline
\end{tabular}

Phase analysis of the powders was performed by X-ray diffraction technique (XRD; D8-Advance, Bruker, Karlsruhe, Germany) with $\mathrm{Cu}-\mathrm{K} \alpha$ radiation $(\lambda=0.15418)$. The thermal stability of the powders was measured by differential scanning calorimetry (DSC; STA449C, NETSCH, Bavaria, Germany) under a high-purity argon atmosphere at a heating rate of $10 \mathrm{~K} / \mathrm{min}$. The microstructure was examined using scanning electron microscope (SEM; Quanta 2000; FEI (Thermo Fisher Scientific), Hillsboro, OR, USA) with energy-dispersive X-ray spectroscopy (EDS; FEI (Thermo Fisher Scientific), Hillsboro, OR, USA). By measuring the dimensions of at least 60 particles for each milled sample, the average particle size and size distribution of the powders were evaluated. Microhardness measurements were conducted by a computer-controlled SCTMC Vickers hardness tester (Shanghai Shangcai, Shanghai, China) using a load of $25 \mathrm{~g}$ and indenter dwell time of $15 \mathrm{~s}$. The microhardness test of each sample 
includes the arithmetic mean of 20 successive indentations, and at least three samples were tested for each parameter. The volume fraction was calculated from the SEM micrographs; at least five measurements were conducted for each sample.

\section{Results and Discussion}

\subsection{Raw Material Morphology}

The micrographs of $\mathrm{Ti}_{52} \mathrm{Cu}_{20} \mathrm{Ni}_{17} \mathrm{Al}_{11}$ powders and gas-atomized $\mathrm{Al} 7075$ powders are shown in Figure 1. The $\mathrm{Ti}_{52} \mathrm{Cu}_{20} \mathrm{Ni}_{17} \mathrm{Al}_{11} \mathrm{MG}$ powders show a near-spherical morphology with a size ranging from $20 \mu \mathrm{m}$ to $50 \mu \mathrm{m}$. The atomized Al7075 powders have a mean particle size of about $10 \mu \mathrm{m}$ and a near spherical morphology.
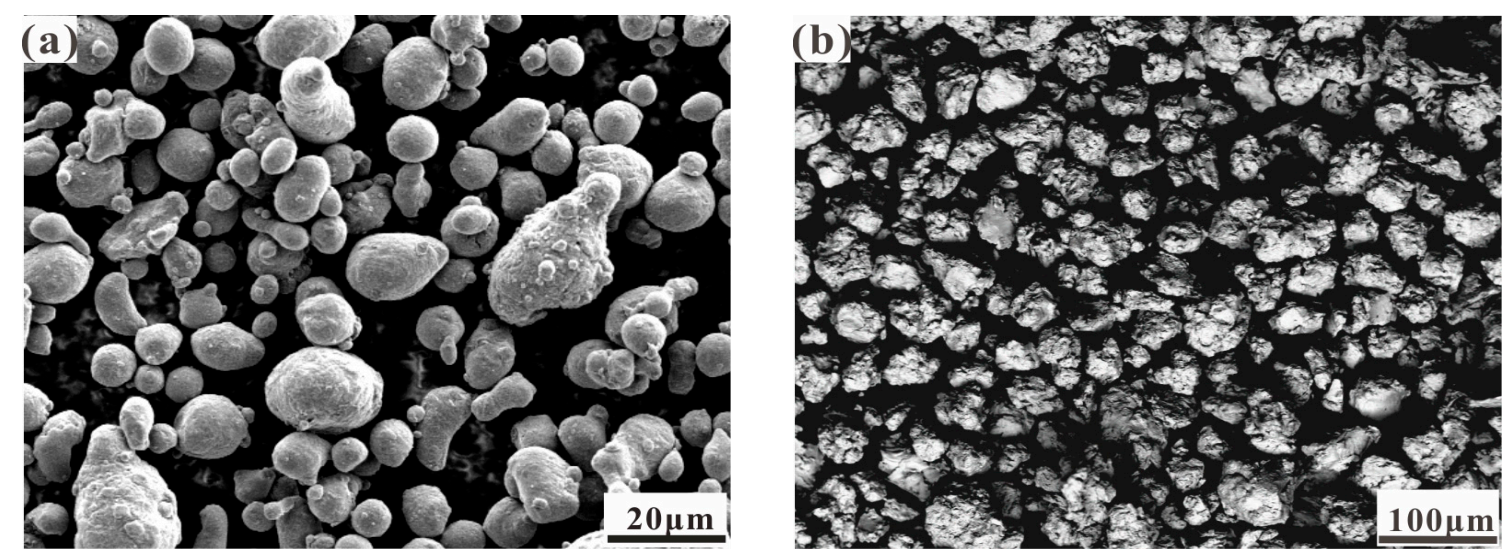

Figure 1. SEM (scanning electron microscope) images: (a) Gas atomized Al7075 powders; (b) as-synthesized $\mathrm{Ti}_{52} \mathrm{Cu}_{20} \mathrm{Ni}_{17} \mathrm{Al}_{11}$ metallic glass powders.

\subsection{Microstructural Observation}

Figure 2 shows the morphological evolution of the composite powders with 8 vol \% glassy reinforcement after being milled for various times. The microstructural features of the milled powders, including their particle shape and particle size, were significantly influenced by the milling process. The size of the composite powders initially increased with an increase in milling time, reaching $\sim 170 \mu \mathrm{m}$ after being milled for $10 \mathrm{~h}$. With a longer milling time, the composite powders were fractured, and the average size decreased intensively, from $170 \mu \mathrm{m}$ to $65 \mu \mathrm{m}$ for the powder milled for $20 \mathrm{~h}$. The composite powders reached a steady state after being milled for about $30 \mathrm{~h}$, where the average particle size had decreased to $23 \mu \mathrm{m}$. A further increase in milling time did not cause a substantial change in particle shape or particle size. Therefore, the composite structure gradually attained a stable state as the milling time exceeded $30 \mathrm{~h}$. The size evolution of the composite with milling time is shown in Figure 3. The shape of flattened aluminum particles gradually changed to an irregular one and finally show a rather equiaxed structure. 

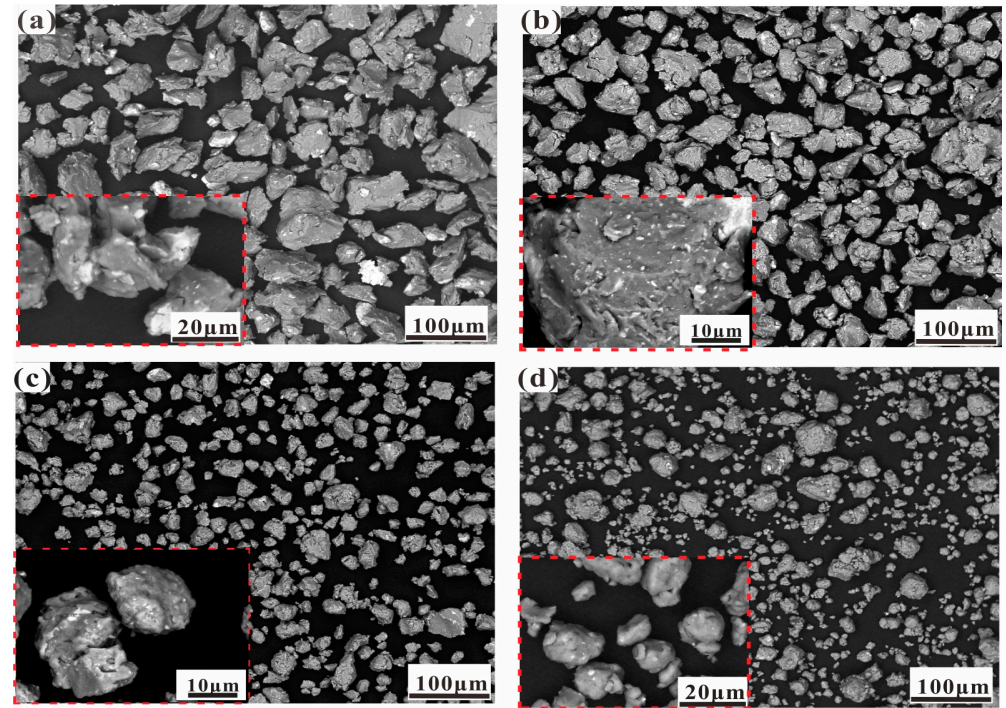

Figure 2. SEM images of the composite powders ( 8 vol \% Ti-based metallic glassy particles and $92 \mathrm{vol} \%$ Al7075 powders) milled for: (a) $10 \mathrm{~h}$; (b) $15 \mathrm{~h}$; (c) $20 \mathrm{~h}$ and (d) $50 \mathrm{~h}$.

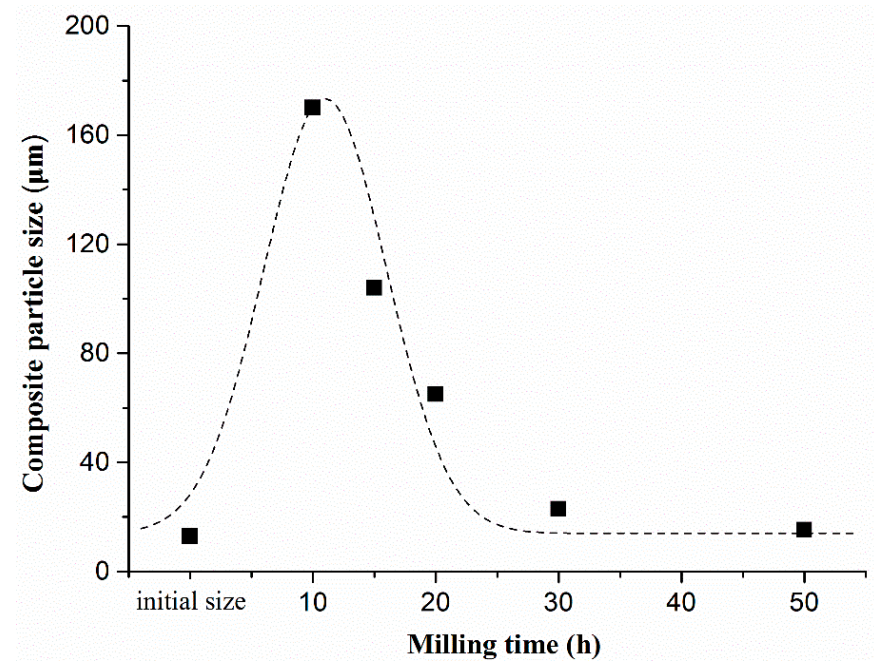

Figure 3. Average particle size of the composite powder versus milling time, the black squares represent the calculated average particle size after certain milling time, the dash line shows size distribution of the powders.

\subsection{X-Ray Diffraction and Differential Scanning Calorimetry Analysis}

Figure 4 shows the XRD patterns of the initial and composite powders milled for different times. The as-synthesized $\mathrm{Ti}_{52} \mathrm{Cu}_{20} \mathrm{Ni}_{17} \mathrm{Al}_{11}$ metallic glass powders are proved to be amorphous by the typical broad diffraction maxima at $2 \theta=40.8^{\circ}$, without any detectable crystalline Bragg peak. The XRD patterns of the composite powders show sharp Bragg peaks, which corresponds to the Al matrix. No peaks belonging to additional phases can be observed, indicating that the amorphous state of the glassy particles in the composite powders is maintained. Moreover, the Al peaks were broadened, and their intensities gradually decreased with the increased milling time, indicating a gradual reduction in the crystallite size, as well as an increase in the lattice strain, which is in accordance with the typical results of milling aluminum and aluminum alloys [34]. The precipitates $\left(\mathrm{MgZn}_{2}\right)$ in the Al7075 alloy matrix were dissolved with milling, which can also be found in our previous work on $\mathrm{Zr}$-based metallic glass fiber-reinforced AMMCs [1]. 


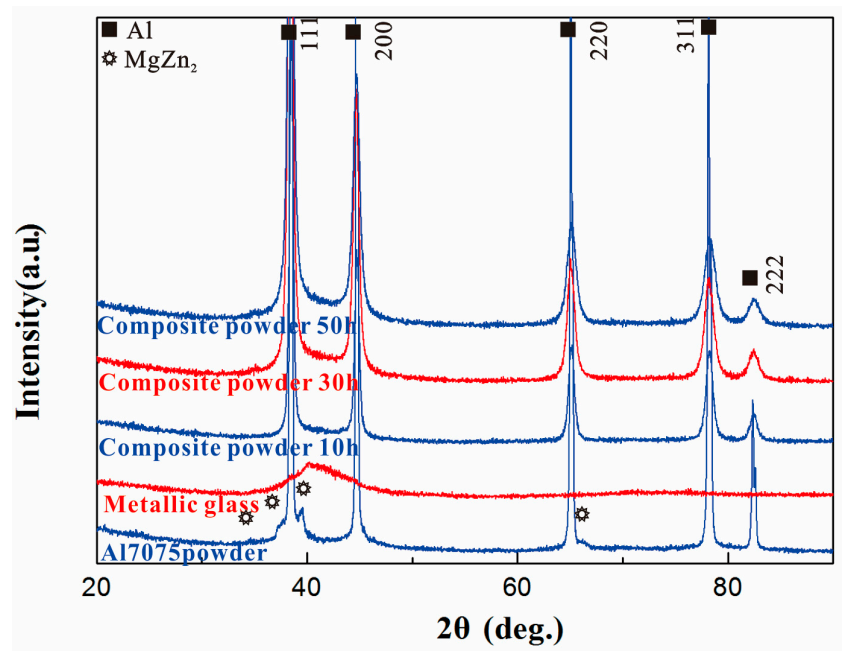

Figure 4. XRD (X-ray diffraction) patterns of the initial and composite powders milled for different times.

The amorphous nature of the glassy phase in composite powders can also be verified by the DSC results (shown in Figure 5). The $\mathrm{Ti}_{52} \mathrm{Cu}_{20} \mathrm{Ni}_{17} \mathrm{Al}_{11} \mathrm{MG}$ powders display two partial overlap exothermic events with the onset $\left(T_{\mathrm{x}}\right)$ at $716 \mathrm{~K}$, which corresponds to the crystallization of the amorphous phase; it is also close to $718 \mathrm{~K}$, which is the crystallization temperature of $\mathrm{Ti}_{60} \mathrm{Cu}_{15} \mathrm{Ni}_{15} \mathrm{Al}_{10}$ metallic glass [35]. At a similar position, weak exothermic peaks exist on the DSC curve of the composite powders, indicating that the Ti-based reinforcing phase remained in an amorphous state during ball milling.

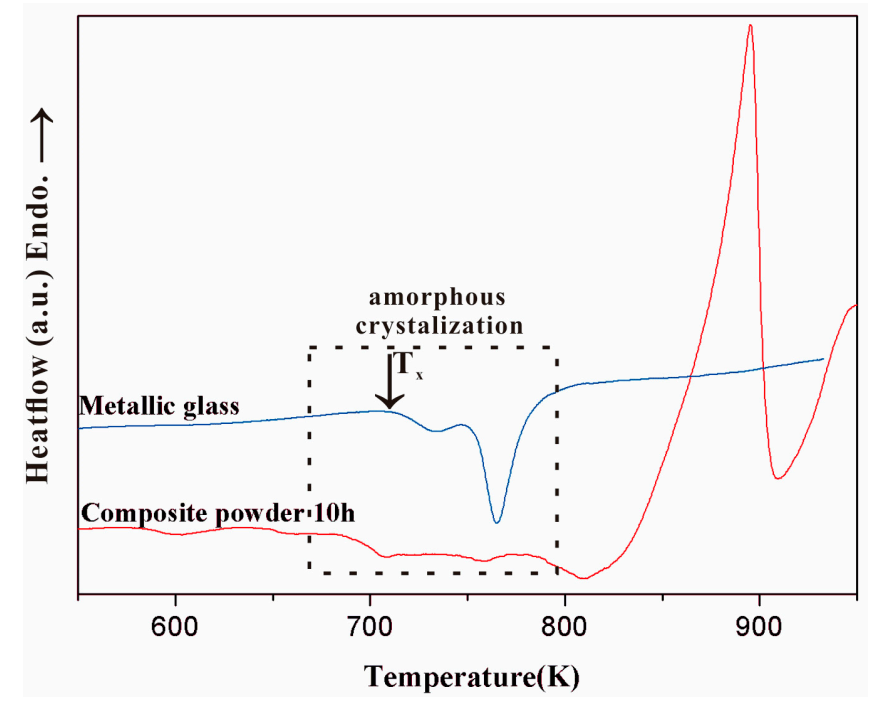

Figure 5. DSC (differential scanning calorimetry) thermograms of the initial Ti-based metallic glass and composite powders, inside the square frame shows two exothermic peaks at similar positions for metallic glass and composite powder respectively.

\subsection{Mechanisms of Morphology Development}

The MG microparticles in the composite powders gradually changed into MG nanoparticles, with milling. The cross-section SEM micrographs of the composite powders are shown in Figure 6. The bright phase corresponds to the MG particles, while the dark phase corresponds to the Al7075 matrix alloy. At the initial milling stage $(<10 \mathrm{~h})$, the Al7075 matrix alloy powders $(\sim 10 \mu \mathrm{m})$ were cold-welded, and grew; meanwhile, the MG microparticles were captured by the coarser Al7075 matrix 
alloy powders (Figure 6a). During milling, severe plastic deformation occurred at the surface of the composite powders, which suffered high-energy impacts [34]. Severe plastic deformation also can occur, firstly at the surface of pure amorphous powder, and form a deformed surface layer [36]. Therefore, a deformed layer formed, and its thickness increased with increasing milling time. The deformed layer is shown in Figure 6. The area fraction of the deformed layer with milling time is shown in Figure 7. The MG microparticles were fractured into submicro- and/or nano- particles, owing to the large shear deformation in the deformed layer, whereas the center part of the composite powders remained undeformed or less deformed where the MG microparticles remained micro size.
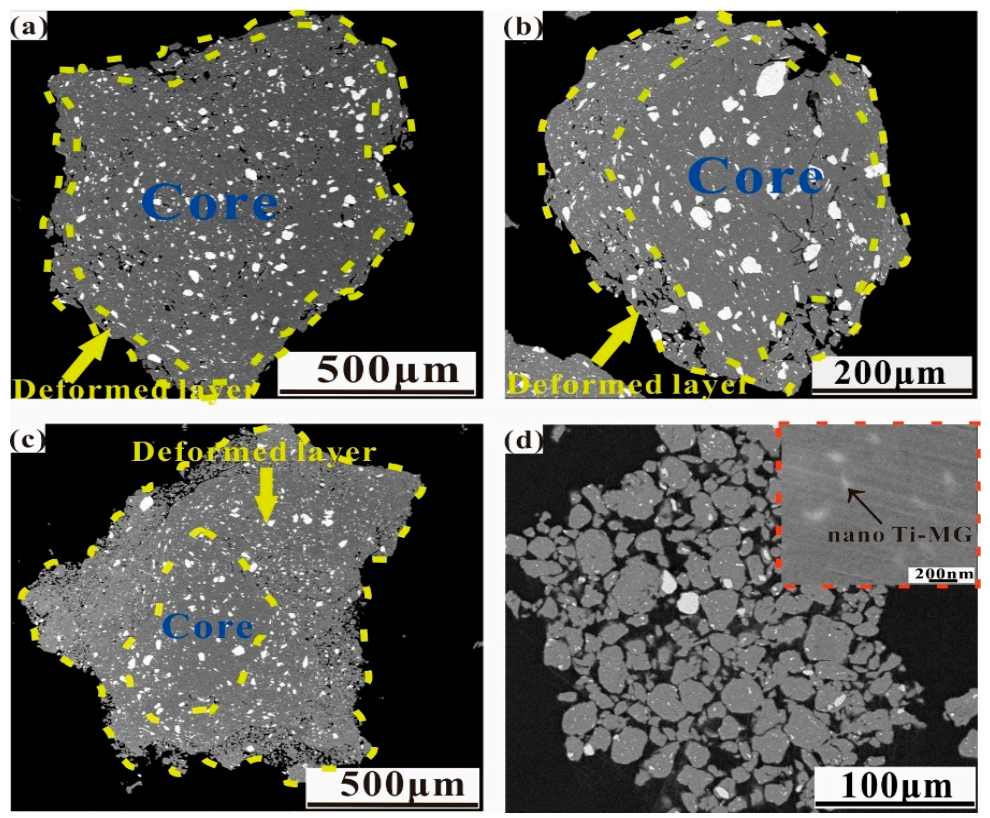

Figure 6. SEM micrographs of the cross sections of the composite powders milled after: (a) $10 \mathrm{~h}$; (b) $15 \mathrm{~h}$; (c) $20 \mathrm{~h}$; (d) $30 \mathrm{~h}$ (MG: Metallic glass).

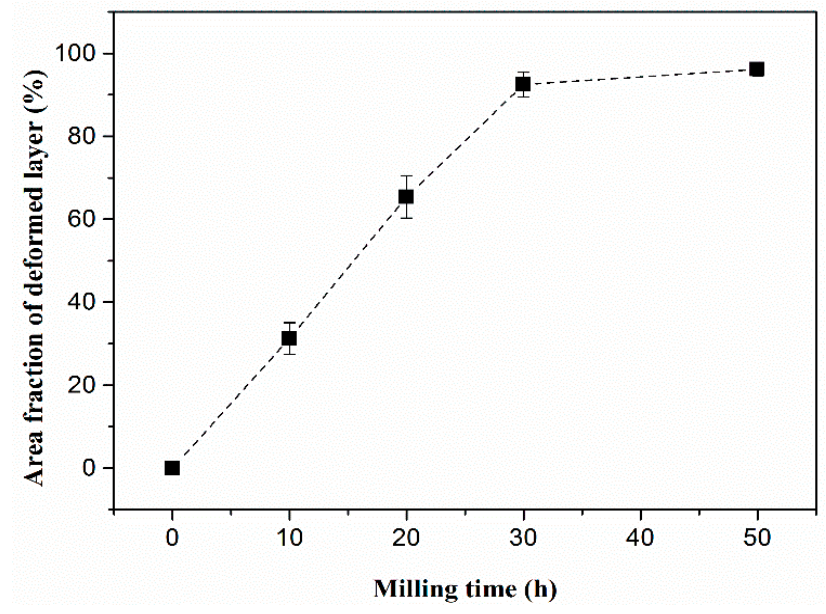

Figure 7. The area fraction of the deformed layer with different milling time.

As is shown in Figure 6, the composite powders were broken into many smaller powders when the milling time was increased to more than $30 \mathrm{~h}$. The main reason for this is that cold working enhanced with milling, which would result in work hardening [34]. Therefore, the composite powders became more and more brittle with increasing milling time, and gradually fractured into many smaller powders, which can be clearly seen in Figure 6d. A phenomenon was also observed, in the 
mechanical milling of $\mathrm{Al}-\mathrm{B}_{4} \mathrm{C}$ nanocomposite powders, whereby large particles became brittle in the late milling stage, and then gradually fractured [37]. Fractured small powders further facilitate plastic deformation, and therefore a dense and uniform dispersion of MG nanoparticles in the matrix ultimately formed. The morphological and microstructure changes in composite powders with milling are further schematically illustrated in Figure 8.

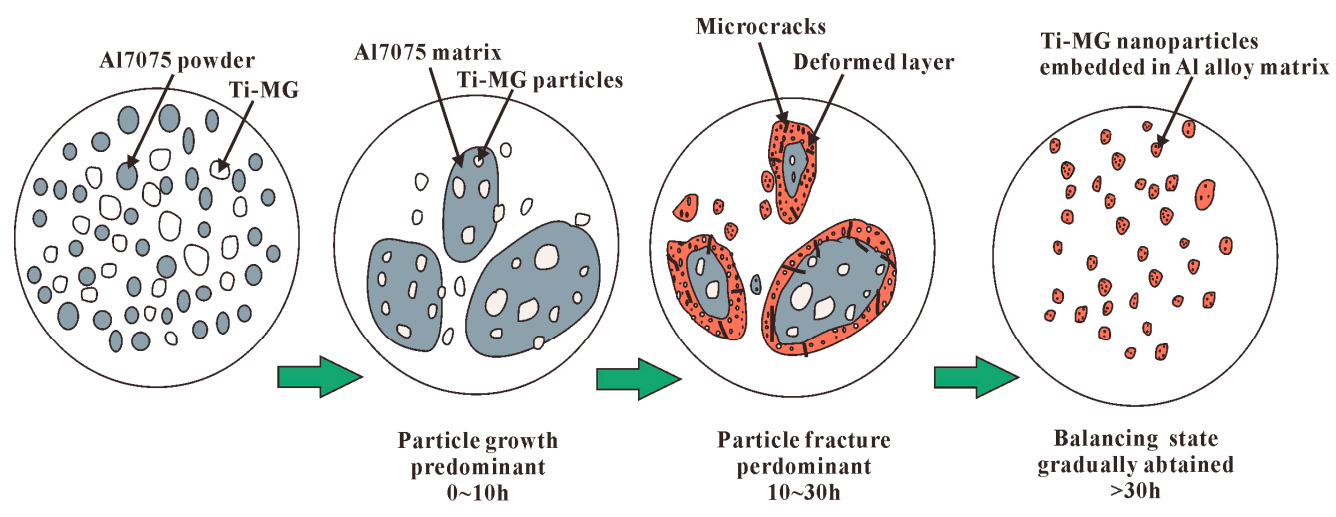

Figure 8. Schematic illustration of the morphological and microstructure evolution in composite powders with milling, the gray parts represent Al7075 powders, the white parts represent Ti-MG particles, the red parts represent the deformed layer caused by plastic deformation.

\subsection{Evaluation of Mechanical Properties}

Microhardness measurements were carried out on the milled composite powders in order to evaluate the mechanical property as a function of milling time, as given in Figure 9. The deformed layer shows a much higher hardness than the less deformed center part (Figure 9b), which shows a mechanical bimodal microstructure. The average hardness of the composite powders is shown in Figure 9a, in which it can be seen that the hardness increased with increasing milling time, from $142 \pm 6.1 \mathrm{HV}$ for unmilled powders to $423 \pm 12.3 \mathrm{HV}$ for the powders milled for $50 \mathrm{~h}$. The increase in hardness can be attributed to the collective consequences of (i) dispersion strengthening: The fragmentation of the nano-sized metallic glass and their uniform dispersion in the matrix are important for achieving high hardness of the composite powder [33]. This observation is in good agreement with the gradually increasing fraction of the deformed layer in which dense and fine MG particles remained; and (ii) Strain hardening: It is noteworthy that severe plastic deformation caused by high-energy ball milling generated higher amounts of lattice defects, such as dislocations, in the $\mathrm{Al}$ matrix [38]. These defects and their interaction with themselves and with the nano-sized metallic glass led to the hardness increment of the composite powder.
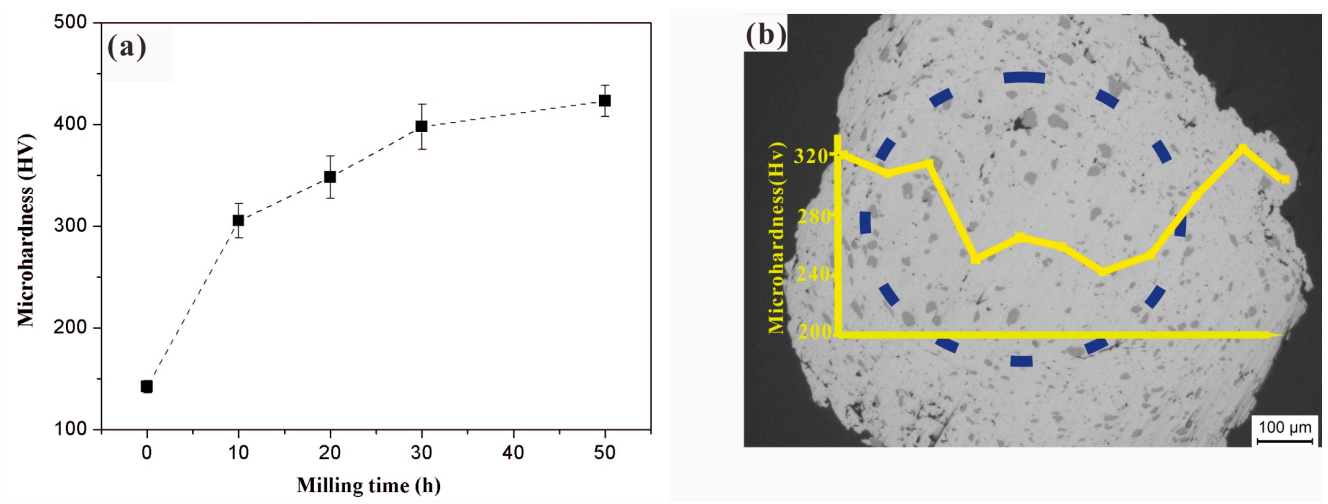

Figure 9. (a) Microhardness of the composite powders as a function of milling time; (b) microhardness distribution within a single composite powder. 


\section{Conclusions}

(1) Al7075 composite powders reinforced by a dense and uniform dispersed nano-scaled Ti-based MG particles were fabricated through ball milling.

(2) The high energy impact between the balls and vials during milling results into severe plastic deformation at the surface of the composite powder. The deformed layer grows with increasing milling time. The MG microparticles are fractured into many submicro- and nanoparticles.

(3) The composite powder milled for a short time shows a mechanical bimodal structure in which the outer deformed layer shows much higher hardness than the less deformed center part.

(4) The average microhardness of the composite powders increases with increasing milling time. The strengthening mechanisms are attributed to dispersion strengthening and strain hardening.

Acknowledgments: The financial support from the Fundamental Research Funds for the Central Universities, Key Project of Scientific and Technological Innovation of Department of Education of Guangdong Province (No. 2012CX2D0010), Team Project of Natural Science Foundation of Guangdong Province (No. 2015A030312003) and Major Special Project for Science and Technology of Guangdong Province (No. 2015B090926004) are acknowledged.

Author Contributions: Yuan $\mathrm{Hu}$ and Guanqun Zhang performed the experiments and analyzed the data; Yuan Hu wrote the original manuscript; Zhi Wang designed the experiments, analyzed the results and revised the manuscript; Weiwen Zhang contributed to all activities.

Conflicts of Interest: The authors declare no conflict of interest.

\section{References}

1. Wang, Z.; Georgarakis, K.; Nakayama, K.S.; Li, Y.; Tsarkov, A.A.; Xie, G.; Dudina, D.; Louzguine-Luzgin, D.V.; Yavari, A.R. Microstructure and mechanical behavior of metallic glass fiber-reinforced Al alloy matrix composites. Sci. Rep. 2016, 6, 24384. [CrossRef] [PubMed]

2. Chawla, N.; Chawla, K.K. Metal Matrix Composites; Springer: New York, NY, USA, 2013.

3. Zheng, R.; Yang, H.; Liu, T.; Ameyama, K.; Ma, C. Microstructure and mechanical properties of aluminum alloy matrix composites reinforced with Fe-based metallic glass particles. Mater. Des. 2014, 53, 512-518. [CrossRef]

4. Yu, P.; Kim, K.B.; Das, J.; Baier, F.; Xu, W.; Eckert, J. Fabrication and mechanical properties of Ni-Nb metallic glass particle-reinforced Al-based metal matrix composite. Scr. Mater. 2006, 54, 1445-1450. [CrossRef]

5. Li, C.; Liu, X.; Yi, J.; Teng, L.; Bao, R.; Tan, J.; Yang, C.; Zou, Z. Effects of sintering parameters on the microstructure and mechanical properties of carbon nanotubes reinforced aluminum matrix composites. J. Mater. Res. 2016, 31, 3757-3765. [CrossRef]

6. Nishida, Y. Introduction to Metal Matrix Composites: Fabrication and Recycling; Springer: Tokyo, Japan, 2013.

7. Ibrahim, I.A.; Mohamed, F.A.; Lavernia, E.J. Particulate reinforced metal matrix composites-A review. J. Mater. Sci. 1991, 26, 1137-1156. [CrossRef]

8. Hong, S.; Kim, H.; Huh, D.; Suryanarayana, C. Effect of clustering on the mechanical properties of SiC particulate-Reinforced aluminum alloy 2024 metal matrix composites. Mater. Sci. Eng. A 2003, 347, 198-204. [CrossRef]

9. Christman, T.; Needleman, A.; Nutt, S.; Suresh, S. On microstructural evolution and micromechanical modelling of deformation of a whisker-reinforced metal-matrix composite. Mater. Sci. Eng. A 1989, 107, 49-61. [CrossRef]

10. Inoue, A. Bulk amorphous and nanocrystalline alloys with high functional properties. Mater. Sci. Eng. A 2001, 304-306, 1-10. [CrossRef]

11. Slipenyuk, A.; Kuprin, V.; Milman, Y.; Goncharuk, V.; Eckert, J. Properties of P/M processed particle reinforced metal matrix composites specified by reinforcement concentration and matrix-to-reinforcement particle size ratio. Acta Mater. 2006, 54, 157-166. [CrossRef]

12. Wang, Z.; Tan, J.; Sun, B.A.; Scudino, S.; Prashanth, K.G.; Zhang, W.W.; Li, Y.Y.; Eckert, J. Fabrication and mechanical properties of Al-based metal matrix composites reinforced with $\mathrm{Mg}_{65} \mathrm{Cu}_{20} \mathrm{Zn}_{5} \mathrm{Y}_{10}$ metallic glass particles. Mater. Sci. Eng. A 2014, 600, 53-58. [CrossRef] 
13. Markó, D.; Prashanth, K.G.; Scudino, S.; Wang, Z.; Ellendt, N.; Uhlenwinkel, V.; Eckert, J. Al-based metal matrix composites reinforced with $\mathrm{Fe}_{49.9} \mathrm{Co}_{35.1} \mathrm{Nb}_{7.7} \mathrm{~B}_{4.5} \mathrm{Si}_{2.8}$ glassy powder: Mechanical behavior under tensile loading. J. Alloys Compd. 2015, 615, S382-S385. [CrossRef]

14. Aljerf, M.; Georgarakis, K.; Louzguine-Luzgin, D.; Le Moulec, A.; Inoue, A.; Yavari, A.R. Strong and light metal matrix composites with metallic glass particulate reinforcement. Mater. Sci. Eng. A 2012, 532, 325-330. [CrossRef]

15. Scudino, S.; Liu, G.; Prashanth, K.G.; Bartusch, B.; Surreddi, K.B.; Murty, B.S.; Eckert, J. Mechanical properties of Al-based metal matrix composites reinforced with $\mathrm{Zr}$-based glassy particles produced by powder metallurgy. Acta Mater. 2009, 57, 2029-2039. [CrossRef]

16. Lee, M.H.; Kim, J.H.; Park, J.S.; Kim, W.T.; Kim, D.H. Development of Ni-Nb-Ta metallic glass particle reinforced Al based matrix composites. In Proceedings of the Pricm 5: The Fifth Pacific Rim International Conference on Advanced Materials and Processing, Pts 1-5, Beijing, China, 2-5 November 2004; Trans Tech Publications: Zurich, Switzerland, 2005; Volumes 475-479, pp. 3427-3430.

17. Bae, D.H.; Kim, S.H.; Kim, D.H.; Kim, W.T. Deformation behavior of Mg-Zn-Y alloys reinforced by icosahedral quasicrystalline particles. Acta Mater. 2002, 50, 2343-2356. [CrossRef]

18. Wang, Z.; Prashanth, K.G.; Chaubey, A.K.; Lober, L.; Schimansky, F.P.; Pyczak, F.; Zhang, W.W.; Scudino, S.; Eckert, J. Tensile properties of Al-12Si matrix composites reinforced with Ti-Al-based particles. J. Alloy. Compd. 2015, 630, 256-259. [CrossRef]

19. Sun, B.A.; Wang, W.H. The fracture of bulk metallic glasses. Prog. Mater. Sci. 2015, 74, 211-307. [CrossRef]

20. Wang, Z.; Scudino, S.; Stoica, M.; Zhang, W.; Eckert, J. Al-based matrix composites reinforced with short Fe-based metallic glassy fiber. J. Alloy. Compd. 2015, 651, 170-175. [CrossRef]

21. Lee, M.H.; Kim, J.H.; Park, J.S.; Kim, J.C.; Kim, W.T.; Kim, D.H. Fabrication of Ni-Nb-Ta metallic glass reinforced Al-based alloy matrix composites by infiltration casting process. Scr. Mater. 2004, 50, 1367-1371. [CrossRef]

22. Balc1, Ö.; Prashanth, K.; Scudino, S.; Ağaoğulları, D.; Duman, İ.; Öveçoğlu, M.; Uhlenwinkel, V.; Eckert, J. Effect of milling time and the consolidation process on the properties of $\mathrm{Al}$ matrix composites reinforced with Fe-based glassy particles. Metals 2015, 5, 669-685. [CrossRef]

23. Gupta, P.; Pal, S.; Yedla, N. Molecular dynamics based cohesive zone modeling of Al (metal)-Cu50Zr50 (metallic glass) interfacial mechanical behavior and investigation of dissipative mechanisms. Mater. Des. 2016, 105, 41-50. [CrossRef]

24. Rezaei, M.R.; Razavi, S.H.; Shabestari, S.G. Development of a novel Al-Cu-Ti metallic glass reinforced Al matrix composite consolidated through equal channel angular pressing (ECAP). J. Alloy. Compd. 2016, 673, 17-27. [CrossRef]

25. Zhang, L.; Yang, L.K.; Leng, J.; Wang, T.; Wang, Y. Alloying behavior and properties of Al-based composites reinforced with $\mathrm{Al}_{85} \mathrm{Fe}_{15}$ metallic glass particles fabricated by mechanical alloying and hot pressing consolidation. JOM 2017, 69, 748-755. [CrossRef]

26. Dudina, D.V.; Georgarakis, K.; Li, Y.; Aljerf, M.; LeMoulec, A.; Yavari, A.R.; Inoue, A. A magnesium alloy matrix composite reinforced with metallic glass. Compos. Sci. Technol. 2009, 69, 2734-2736. [CrossRef]

27. Kim, J.Y.; Scudino, S.; Kühn, U.; Kim, B.S.; Lee, M.H.; Eckert, J. Production and characterization of brass-matrix composites reinforced with $\mathrm{Ni}_{59} \mathrm{Zr}_{20} \mathrm{Ti}_{16} \mathrm{Si}_{2} \mathrm{Sn}_{3}$ glassy particles. Metals 2012, 2, 79-94. [CrossRef]

28. Tomolya, K.; Sycheva, A.; Sveda, M.; Arki, P.; Miko, T.; Roosz, A.; Janovszky, D. Synthesis and characterization of copper-based composites reinforced by $\mathrm{CuZrAlNiTi}$ amorphous particles with enhanced mechanical properties. Metals 2017, 7, 92. [CrossRef]

29. Subramanian, J.; Seetharaman, S.; Gupta, M. Processing and properties of aluminum and magnesium based composites containing amorphous reinforcement: A review. Metals 2015, 5, 743-762. [CrossRef]

30. Wang, Z.; Tan, J.; Scudino, S.; Sun, B.A.; Qu, R.T.; He, J.; Prashanth, K.G.; Zhang, W.W.; Li, Y.Y.; Eckert, J. Mechanical behavior of Al-based matrix composites reinforced with $\mathrm{Mg}_{58} \mathrm{Cu}_{28.5} \mathrm{Gd}_{11} \mathrm{Ag}_{2.5}$ metallic glasses. Adv. Powder Technol. 2014, 25, 635-639. [CrossRef]

31. Casati, R.; Vedani, M. Metal matrix composites reinforced by nano-particles-A review. Metals 2014, 4, 65-83. [CrossRef]

32. Lan, J.; Yang, Y.; Li, X. Microstructure and microhardness of SiC nanoparticles reinforced magnesium composites fabricated by ultrasonic method. Mater. Sci. Eng. A 2004, 386, 284-290. [CrossRef] 
33. Chen, L.Y.; Xu, J.Q.; Choi, H.; Pozuelo, M.; Ma, X.; Bhowmick, S.; Yang, J.M.; Mathaudhu, S.; Li, X.C. Processing and properties of magnesium containing a dense uniform dispersion of nanoparticles. Nature 2015, 528, 539-543. [CrossRef] [PubMed]

34. Suryanarayana, C. Mechanical alloying and milling. Prog. Mater. Sci. 2001, 46, 1-184. [CrossRef]

35. Nguyen, H.V.; Kim, J.S.; Kwon, Y.S.; Kim, J.C. Amorphous Ti-Cu-Ni-Al alloys prepared by mechanical alloying. J. Mater. Sci. 2009, 44, 2700-2704. [CrossRef]

36. Wang, Z.; Qu, R.T.; Scudino, S.; Sun, B.A.; Prashanth, K.G.; Louzguine-Luzgin, D.V.; Chen, M.W.; Zhang, Z.F.; Eckert, J. Hybrid nanostructured aluminum alloy with super-high strength-Supporting information. NPG Asia Mater. 2015, 7, e229. [CrossRef]

37. Alihosseini, H.; Dehghani, K. Analysis of particle distribution in milled Al-based composites reinforced by $\mathrm{B}_{4} \mathrm{C}$ nanoparticles. J. Mater. Eng. Perform. 2017, 26, 1856-1864. [CrossRef]

38. Miller, W.S.; Humphreys, F.J. Strengthening mechanisms in particulate metal-matrix composites. Scr. Metall. Mater. 1991, 25, 33-38. [CrossRef]

(C) 2017 by the authors. Licensee MDPI, Basel, Switzerland. This article is an open access article distributed under the terms and conditions of the Creative Commons Attribution (CC BY) license (http://creativecommons.org/licenses/by/4.0/). 